\title{
Response of Thawed Epididymal Red Deer Spermatozoa to Increasing Concentrations of Hydrogen Peroxide, and Importance of Individual Male Variability
}

\author{
AE Domínguez-Rebolledo ${ }^{1}$, F Martínez-Pastor ${ }^{2}$, AF Bisbal ${ }^{1}$, JL Ros-Santaella ${ }^{1}$, O García-Álvarez ${ }^{3}$, A Maroto-Morales ${ }^{1}$, \\ AJ Soler ${ }^{1}$, JJ Garde ${ }^{1,4}$ and MR Fernández-Santos ${ }^{1,4}$ \\ ${ }^{1}$ Reproductive Biology Group, National Wildlife Research Institute (IREC), UCLM-CSIC-JCCM, Albacete; ${ }^{2}$ ITRA-ULE, INDEGSAL, University \\ of Leon, León; ${ }^{3}$ Regional Center of Animal Selection and Reproduction (CERSYRA), JCCM, Valdepeñas, Ciudad Real; ${ }^{4}$ Institute of Regional \\ Development (IDR), UCLM, Albacete, Spain
}

\begin{abstract}
Contents
Oxidative stress represents a challenge during sperm manipulation. We have tested the effect of increasing hydrogen peroxide $\left(\mathrm{H}_{2} \mathrm{O}_{2}\right)$ levels on red deer spermatozoa after cryopreservation, and the role of male-to-male variation in that response. In a first experiment, eight thawed samples were submitted to $0,25,50,100$ and $200 \mu \mathrm{M} \mathrm{H}_{2} \mathrm{O}_{2}$ for $2 \mathrm{~h}$ at $37^{\circ} \mathrm{C}$. Intracellular reactive oxygen species $\left(\mathrm{H}_{2}\right.$ DCFDA-CM) increased with $\mathrm{H}_{2} \mathrm{O}_{2}$ concentration, but we only detected a decrease in sperm function (motility by CASA and chromatin damage by sperm chromatin structure assay) with $200 \mu \mathrm{M}$. Lipoperoxidation (TBARS) increased slightly with $50 \mu \mathrm{m}$ $\mathrm{H}_{2} \mathrm{O}_{2}$ and above. In a second experiment, samples from seven males were submitted to 0 and $200 \mu \mathrm{M} \quad \mathrm{H}_{2} \mathrm{O}_{2}$ for $2 \mathrm{~h}$, triplicating the experiment within each male. Males differed at thawing and regarding their response to incubation and $\mathrm{H}_{2} \mathrm{O}_{2}$ presence. We found that the kinematic parameters reflected male-to-male variability, whereas the response of the different males was similar for lipid peroxidation and viability. A multiparametric analysis showed that males grouped differently if samples were assessed after thawing, after incubation without $\mathrm{H}_{2} \mathrm{O}_{2}$ or after incubation with $\mathrm{H}_{2} \mathrm{O}_{2}$. Red deer spermatozoa are relatively resilient to $\mathrm{H}_{2} \mathrm{O}_{2}$ after thawing, but it seems to be a great male-to-male variability regarding the response to oxidative stress. The acknowledgement of this individual variability might improve the development of optimized sperm work protocols.
\end{abstract}

\section{Introduction}

Oxidative stress is one of the major threats to sperm functionality, both in vivo and in vitro. Reactive oxygen species (ROS) have a fundamental role in sperm physiology, but in excess they can damage spermatozoa (Agarwal and Saleh 2002). Reactive oxygen species can be detrimental even within physiological levels, since they may trigger early capacitation and irreversible events, such as acrosome reaction (Hsu et al. 1999). Researchers generally use external sources of ROS to study oxidative stress on spermatozoa such as hydrogen peroxide $\left(\mathrm{H}_{2} \mathrm{O}_{2}\right)$, a potent membrane-permeable oxidizing species (Oehninger et al. 1995). Armstrong et al. (1999) found that hydrogen peroxide was not only responsible for the loss of motility, but also it caused the loss of mitochondrial membrane potential. Moreover, ROS, including $\mathrm{H}_{2} \mathrm{O}_{2}$, have dual effects on mammalian sperm. Low concentrations of ROS exogenously added are believed to play a stimulatory role in sperm capacitation (Rivlin et al. 2004), hyperactivation (De Lamirade and Gagnon 1994), acrosome reaction
(Griveau et al. 1995) and sperm-oocyte fusion (Aitken et al. 1995). However, excessive levels of ROS are linked to impaired sperm function and infertility (Sharma et al. 2004). Reactive oxygen species can be also detrimental to sperm DNA integrity (Baumber et al. 2003; Dominguez-Rebolledo et al. 2010a,b).

It has been previously reported by our own group that different ROS generators affected quality parameters differently in red deer, showing that hydrogen peroxide $\left(\mathrm{H}_{2} \mathrm{O}_{2}\right)$ was more cytotoxic to red deer spermatozoa than $\mathrm{Fe}^{2+}$ /ascorbate (Martinez-Pastor et al. 2009a). Moreover, motility and mitochondrial membrane potential were quickly decreased by $\mathrm{H}_{2} \mathrm{O}_{2}$ (1 $\mathrm{mm}$ and $100 \mu \mathrm{M})$, and only $\mathrm{H}_{2} \mathrm{O}_{2}(1 \mathrm{~mm})$ was able to reduce sperm viability. Thus, the present study was designed to deepen on our previous results, analysing a broader range of $\mathrm{H}_{2} \mathrm{O}_{2}$ concentrations.

Moreover, between-male variability represents a challenge for sperm cryopreservation, because that variability can affect spermatozoa cryosurvival (Soler et al. 2003) and fertility (Malo et al. 2005; Gomendio et al. 2006). That is probably because of differences regarding sperm biochemistry and metabolism (Loomis and Graham 2008), rooting in the genetic variability of individuals. The male-to-male variability could also affect the resistance of spermatozoa to oxidative stress, for instance through changes in the composition of sperm membranes (Waterhouse et al. 2006). In fact, high polyunsaturated fatty acids levels have been related to higher vulnerability to ROS (Ollero et al. 2001), and previous studies have shown that fatty acid profiles could be modified in deers exposed to heavy metals (Castellanos et al. 2010).

Thus, in the present study, we used thawed epididymal spermatozoa of Iberian red deer (Cervus elaphus hispanicus) to test the hypothesis that increasing concentrations of $\mathrm{H}_{2} \mathrm{O}_{2}$ affected differently to sperm characteristics, seeking for endpoints in which $\mathrm{H}_{2} \mathrm{O}_{2}$ could noticeably affect spermatozoa. It is well known that epididymal spermatozoa are not exposed to the complex secretions of the accessory sex glands (seminal plasma), which are recognized as the prime source of antioxidant protection (Chen et al. 2003). In this respect, it is needed a better understanding of the spermatozoa behaviour against oxidative damage, because this damage represents a serious challenge for these unprotected cells when they are outside the epididymal environment. Moreover, spermatozoa might be submitted to stressing

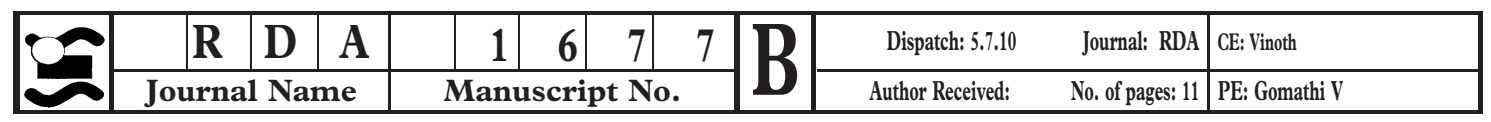


situations during in vitro procedures (in vitro fertilization or sorting), which could increase ROS and other oxidative species. Therefore, this study could be useful to simulate the response of epididymal red deer spermatozoa to oxidative stress in vitro, allowing to explore procedures to alleviate it.

In the present work, it has been also tested if male-tomale variability reflects on the spermatozoa response to $\mathrm{H}_{2} \mathrm{O}_{2}$, expecting to observe this effect when submitting samples from different males to oxidative stress. Being a wild species, we have the advantage of working with samples coming from unselected populations, thus allowing us to better analyse that kind of variability (Garde et al. 2006).

\section{Materials and Methods \\ Reagents and media}

CM-H ${ }_{2}$ DCFDA, YO-PRO-1 and TO-PRO-3 were purchased from Invitrogen (Barcelona, Spain). Flow cytometry equipment, software and consumables (including the sheath fluid, BD FACSFlow) were purchased from BD Biosciences (San Jose, CA, USA). Acridine orange (chromatographically purified) was purchased from Polysciences Inc. (Warrington, PA, USA). Other fluorescence probes and chemicals (high grade) were obtained from Sigma Chemical Co. (Madrid, Spain). Stock solutions of the fluorescence probes were as follows: propidium iodide, $7.5 \mathrm{~mm}$ in water; CM-H ${ }_{2}$ DCFDA, $0.5 \mathrm{~mm}$ in DMSO; YO-PRO-1 and TO-PRO-3, $50 \mu \mathrm{M}$ in DMSO. All solutions were stored at $-20^{\circ} \mathrm{C}$ and in the dark until needed, except oxidant working solutions, which were prepared the same day. Preparation and staining of samples for flow cytometric analysis were performed by flow cytometer PBS (BD FACSFlow; BD Biosciences).

\section{Animals, spermatozoa collection and cryopreservation}

For this study, we used spermatozoa recovered from the epididymides of mature stags (age $>4.5$ years, weight $>130 \mathrm{~kg}$ ) that were legally culled and hunted in their natural habitat during the rutting season (September-October). Gamekeepers collected the complete male genitalia and provided the hour of the death. Hunting was in accordance with the harvest plan of the game reserve, which made following Spanish Harvest Regulation, Law 2/93 of Castilla-La Mancha, which conforms to European Union Regulation.

Immediately upon removal, the testes with attached epididymides were placed into plastic bags and transported to the laboratory at ambient temperature (approximately $22^{\circ} \mathrm{C}$ ) within $2 \mathrm{~h}$ after being removed. The samples were processed as soon as they arrived at the laboratory. The elapsed time between animal death and sperm recovery ranged from 3 to $6 \mathrm{~h}$, which is an adequate and reliable time interval for evaluating sperm parameters, as decreases in the quality of sperm traits begin to take place $12 \mathrm{~h}$ after the death of a male (Soler and Garde 2003). For the collection of epididymal spermatozoa, the testes and epididymides were removed from the scrotal sac. The cauda epididymides, which included 5-10 $\mathrm{cm}$ of the proximal ductus deferens, were separated and transferred to $35-\mathrm{mm}$ plastic dishes (Nunc, Roskilde, Denmark).

Spermatozoa were collected from the distal portion of the epididymis as described by Soler et al. (2003). Epididymal contents from both testicles of the same male were pooled for processing. Then, the sperm mass was diluted to a sperm concentration $\sim 400 \times$ $10^{6} \mathrm{sperm} / \mathrm{ml}$ in fraction A of a Tris-Citrate-Fructose (TCF: Tris $27.0 \mathrm{~g} / 1$, citric acid $14.0 \mathrm{~g} / 1$, fructose $10.0 \mathrm{~g} / 1$ and $20 \%$ clarified egg yolk) (Fernandez-Santos et al. 2006). Then, the diluted sperm was further diluted with the same volume of Fraction B of the extender $(12 \%$, $\mathrm{v} / \mathrm{v}$ of glycerol), at ambient temperature $\left(22^{\circ} \mathrm{C}\right)$. Samples were cooled down to $5^{\circ} \mathrm{C}$ and, after $2 \mathrm{~h}$ of equilibration, were loaded into $0.25 \mathrm{-ml}$ plastic straws (IMV, L'Aigle Cedex, France) and frozen in liquid nitrogen vapour $\left(4 \mathrm{~cm}\right.$ above liquid nitrogen; $\left.-120^{\circ} \mathrm{C}\right)$ for $10 \mathrm{~min}$. The straws remained for a minimum period of 1 year in liquid nitrogen $\left(-196^{\circ} \mathrm{C}\right)$. Thawing was carried out by immersing straws in a water bath at $37^{\circ} \mathrm{C}$ for $30 \mathrm{~s}$.

\section{Experimental Design}

\section{Experiment 1. Effects of increasing doses of $\mathrm{H}_{2} \mathrm{O}_{2}$ on} thawed epididymal spermatozoa from red deer

Experiment 1 was designed to explore the effect of several $\mathrm{H}_{2} \mathrm{O}_{2}$ concentrations on sperm parameters after thawing and to evaluate the relation of $\mathrm{H}_{2} \mathrm{O}_{2}$ with sperm parameters. Thawed semen was washed in TCF $(300 \times g, 5 \mathrm{~min})$ and diluted in the same medium to $30 \times 10^{6}$ spermatozoa $/ \mathrm{ml}$. The sperm solution was split among 5 aliquots in microtubes. One of them was left untreated as the control. The other aliquots were subjected to oxidative stress by adding $\mathrm{H}_{2} \mathrm{O}_{2}$ in four concentrations $(25,50,100$ and $200 \mu \mathrm{M})$. With this approach, we seeked to expand the study initiated previously (Martinez-Pastor et al. 2009a), exploring concentrations between $10 \mu \mathrm{M}$ (which had no negative effects in that study) and $1 \mathrm{~mm}$ (which was patently cytotoxic). All treatments were split into two aliquots. One of them was incubated with $0.5 \mu_{\mathrm{M} \mathrm{H}} \mathrm{H}_{2}$ DCFDA (for assessing ROS production), and the other was used to evaluated the rest of sperm parameters. The microtubes were incubated at $37^{\circ} \mathrm{C}$ and analysed $120 \mathrm{~min}$ after starting the incubation (the control was analysed at 0 and $120 \mathrm{~min}$ ). This experiment was replicated 8 times with samples from eight different males (one straw per male).

\section{Experiment 2. Individual male-to-male variation in the response to oxidative stress}

This experiment evaluated the presence of male to male individual differences on the effect of oxidative stress. Thawed semen was washed in TCF $(300 \times \boldsymbol{g}, 5 \mathrm{~min}$. and diluted in the same medium to $30 \times 10^{6}$ spermato$\mathrm{zoa} / \mathrm{ml}$. The sperm solution was split among two aliquots in microtubes. One of them was left untreated as control, and the other was incubated with $200 \mu \mathrm{m}$ $\mathrm{H}_{2} \mathrm{O}_{2}$ at $37^{\circ} \mathrm{C}$, evaluating the samples after $120 \mathrm{~min}$. The experiment was replicated with samples from seven 
males, with triplicates within each male, using a different cryopreserved straw each time.

\section{Sperm evaluation}

\section{Sperm motility}

Sperm motility was assessed using a computer-assisted motility analyzer (SCA2002, CASA system; Microptic, Barcelona, Spain) coupled to an optical phase-contrast microscope (Nikon Eclipse 80i), equipped with negative phase-contrast objectives, a warming stage at $37^{\circ} \mathrm{C}$ and a Basler A302fs camera (Basler Vision Technologies, Ahrensburg, Germany). A pre-warmed Makler counting chamber $(10 \mu \mathrm{m}$ depth) was loaded with $5 \mu \mathrm{l}$ of sample and analysed. The parameters used in this study were percentage of motile spermatozoa (total motility, TM, $\%$ ), velocity according to the actual path ( $\mathrm{VCL}, \mu \mathrm{m} / \mathrm{s})$, linearity (LIN, \%) and amplitude of the lateral displacement of the sperm head (ALH, $\mu \mathrm{m})$. Sample acquisition rate was 25 images/s, and motile spermatozoa were defined as those with VCL $>10 \mu \mathrm{m} / \mathrm{s}$. At least five fields per sample were recorded and analysed afterwards.

\section{Sperm viability}

Viability was assessed by the monomeric cyanine nucleic acid stain YO-PRO-1. Samples were diluted down to $10^{6}$ spermatozoa/ml in flow cytometry PBS with $0.1 \mu \mathrm{M}$ YO-PRO-1 and $10 \mu \mathrm{M}$ PI. After $20 \mathrm{~min}$ in the dark, the samples were run through a flow cytometer. Labelling cells with the apoptotic marker YO-PRO-1 yielded three subpopulations: viable (unstained: YO-PRO-1/PI-), apoptotic-like membrane changes (YO-PRO$1+/$ PI-) and non-viable (membrane damaged: PI + ). Hoechst 33342 was included at $5.1 \mu \mathrm{m}$.

\section{Detection of ROS}

The derivative of fluorescein, $\mathrm{CM}-\mathrm{H}_{2} \mathrm{DCFDA}$, was used for the detection of ROS. Oxidation of this probe is detected by monitoring the increase in fluorescence with a flow cytometer, using excitation sources and filters appropriate for fluorescein (green fluorescence). This fluorescence probe was combined with TO-PRO-1, a red-fluorescence analogue to YO-PRO-1. Stock solutions of the fluorescence probe were prepared as CM- $\mathrm{H}_{2}$ DCFDA $0.5 \mathrm{~mm}$ in DMSO, TO-PRO-3 $50 \mu \mathrm{m}$ in DMSO, to give a final concentration of $0.5 \mu \mathrm{M}$ of CM- $\mathrm{H}_{2}$ DCFDA and $0.1 \mu \mathrm{M}$ of TO-PRO- 1 . Hoechst 33342 was included at $5.1 \mu \mathrm{M}$.

\section{Flow cytometry analyses}

We used a Becton Dickinson LSR-I flow cytometer (BD Biosciences), furnished with a $325 \mathrm{~nm} \mathrm{He}-\mathrm{Cd}$ (excitation for Hoechst 33342), a $488 \mathrm{~nm} \mathrm{Ar-Ion} \mathrm{laser} \mathrm{(excitation}$ for YO-PRO-1 and PI) and a $633 \mathrm{~nm} \mathrm{He-Ne} \mathrm{laser}$ (excitation for Mitotracker Deep Red). Hoechst 33342 fluorescence was read with the FL5 photodetector (424/44BP filter), YO-PRO-1 and CM- $\mathrm{H}_{2}$ DCFDA fluorescences were read with the FL1 photodetector (530/28BP filter), and PI and TO-PRO-1 fluorescences were read with the FL3 photodetector (670LP filter). FSC/SSC signals and Hoechst fluorescence were used to discriminate spermatozoa from debris. Fluorescence captures were controlled using the Cell Quest Pro 3.1 software (BD Biosciences). All the parameters were read using logarithmic amplification. For each sample, 5000 spermatozoa were recorded at 200 events/s, saving the data in flow cytometry standard (FCS) v. 2 files. The analysis of the flow cytometry data was carried out using WEASEL v. 2.6 (WEHI, Melbourne, Australia). The YO-PRO-1/PI stain was analysed as previously described for red deer (Martinez-Pastor et al. 2008). From this stain, viability was defined as the percentage of membrane intact spermatozoa (PI-) and the 'apoptotic' ratio, as the relation among the YO-PRO$1+/$ PI- and PI- (YO-PRO-1-/PI- plus YO-PRO$1+/$ PI- spermatozoa) subpopulations, expressed as percentage. This ratio estimated the proportion of spermatozoa with apoptosis-like membrane changes within the PI-subpopulation.

\section{Sperm chromatin assessment}

Chromatin stability was assessed following the sperm chromatin structure assay (SCSA), based on the susceptibility of sperm DNA to acid-induced denaturation in situ and on the subsequent staining with the metachromatic fluorescent dye acridine orange (Evenson et al. 1980). Acridine orange (AO) fluorescence shifts from green (dsDNA; double strand) to red (ssDNA; single strand) depending on the degree of DNA denaturation. Samples were diluted in TNE buffer (0.01 M Tris- $\mathrm{HCl}, 0.15 \mathrm{~m} \mathrm{NaCl}, 1 \mathrm{~mm}$ EDTA, pH 7.4) to a final sperm concentration of $2 \times 10^{6}$ cells $/ \mathrm{ml}$ in cryotubes. Samples were frozen in liquid nitrogen and stored in an ultracold freezer at $-80^{\circ} \mathrm{C}$ until needed. For analysis, the samples were thawed on crushed ice. Acidinduced denaturation of DNA in situ was achieved by adding $0.4 \mathrm{ml}$ of an acid-detergent solution $(0.17 \%$ Triton X-100, $0.15 \mathrm{M} \mathrm{NaCl}, 0.08 \mathrm{~N} \mathrm{HCl}, \mathrm{pH} 1.4)$ to $200 \mu \mathrm{l}$ of sample. After $30 \mathrm{~s}$, the cells were stained by adding $1.2 \mathrm{ml}$ of an acridine orange solution $(0.1 \mathrm{M}$ citric acid, $0.2 \mathrm{M} \mathrm{Na}_{2} \mathrm{HPO}_{4}, 1 \mathrm{~mm}$ EDTA, $0.15 \mathrm{M} \mathrm{NaCl}$, $6 \mu \mathrm{g} / \mathrm{ml}$ acridine orange $\mathrm{pH}$ 6.0). The stained samples were analysed by flow cytometry exactly at 3 min after adding the acridine orange solution.

Samples were run through the LSR-I flow cytometer described earlier. Green fluorescence was detected using the FL-1 photodetector and red fluorescence with the FL-3 photodetector. Data were collected from 10000 events at 200 events/s for further analysis with CELLQuEsT software (Becton Dickinson). A tube with $0.4 \mathrm{ml}$ of detergent-acid solution and $1.2 \mathrm{ml}$ of acridine orange solution was run through the system before running any samples and between samples. At the beginning of each session, a standard semen sample was run through the cytometer, and settings were adjusted in order that mean fluorescence values (0-1023 linear scale) for FL-1 and FL-3 were 475 and 125, respectively. Results of the DNA denaturation test were processed to obtain the ratio of red fluorescence to total intensity of the fluorescence $(\mathrm{red} /[\mathrm{red}+$ green $] \times 100)$, called DFI (DNA fragmentation index; formerly called $\alpha t$ ) for each 
spermatozoa, representing the shift from green to red fluorescence. High values of DFI indicate chromatin abnormalities. Flow cytometry data were processed to obtain \% DFI ( $\%$ of spermatozoa with DFI > 25) and high DNA stainability (HDS: \% of spermatozoa with green fluorescence higher than channel 600, of 1024 channels).

\section{TBARS assay for quantification of lipid peroxidation} $2(L P O)$

The susceptibility of the spermatozoa to lipoperoxidation (LPO) was estimated by the thiobarbituric acid reactive substance (TBARS) method according to Ohkawa et al. (1979). Samples of $100 \mu \mathrm{l}$ were thoroughly mixed with $200 \mu \mathrm{l}$ of a stock solution containing $15 \%(\mathrm{w} / \mathrm{v})$ trichloroacetic acid, $0.375 \% \quad(\mathrm{w} / \mathrm{v})$ thiobarbituric acid and $0.25 \mathrm{M} \mathrm{HCl}$. This mixture was heated at $90^{\circ} \mathrm{C}$ for $15 \mathrm{~min}$, and then the reaction was stopped by placing the tubes in ice-cold water for $5 \mathrm{~min}$. The tubes were centrifuged at $1500 \times \boldsymbol{g}$ for 15 min to pellet the precipitate, and the clear supernatant was collected and transferred to wells $(200 \mu \mathrm{l} /$ well $)$ in a 96-well flat bottom transparent plate (Nunc). The plate was completed with a calibration curve prepared from a malondialdehyde (MDA) stock (1,1,3,3-tetramethoxypropane). Sample absorbance at $532 \mathrm{~nm}$ was read on a multipurpose microplate reader (Synergy HT, BIO-TEK, Winooski, VT, USA). Malondialdehyde concentration was calculated from a standard curve. The lipid peroxidation index was calculated as nmol of MDA per $10^{8}$ sperm. This assay was duplicated for each sample.

\section{Statistical analysis}

Statistical analyses were carried out using the R statistical package (http://www.r-project.org). For the analysis of $\mathrm{H}_{2} \mathrm{O}_{2}$ (Experiment 1), data were analysed using linear mixed-effects models, treating the male effect as the random part of the model, and time or $\mathrm{H}_{2} \mathrm{O}_{2}$ concentration as the fixed part of the model. For the analysis of the male-to-male variability (Experiment 2), results were arc sine (proportions) or log-transformed (other variables), and male, treatment (values at 0,2 and $2 \mathrm{~h}$ with $200 \mu \mathrm{M}$ of $\mathrm{H}_{2} \mathrm{O}_{2}$ ) and their interaction were analysed by ANOVA. For the graphical analysis of the data, we used interaction plots and principal component analysis (with TM, VCL, LIN, ALH, LPO and viability). Unless otherwise stated, results are presented as mean \pm SEM, and statistical significance was accepted for $\mathrm{p}<0.05$.

\section{Results}

\section{Experiment 1. Effects of increasing doses of $\mathrm{H}_{2} \mathrm{O}_{2}$ on thawed epididymal spermatozoa from red deer}

We evaluated how increasing $\mathrm{H}_{2} \mathrm{O}_{2}$ concentration affected sperm quality parameters, looking after $\mathrm{H}_{2} \mathrm{O}_{2}$ concentrations that might induce critical changes on sperm quality during incubation. Intracellular ROS (Fig. 1) spontaneously increased from 0 to $2 \mathrm{~h}$ $(210 \pm 12$ at $0 \mathrm{~h}$ and $309 \pm 9$ at $2 \mathrm{~h}$, in mean fluorescence units; $\mathrm{p}<0.001$ ). When $\mathrm{H}_{2} \mathrm{O}_{2}$ was added to the samples, ROS concentration increased with $\mathrm{H}_{2} \mathrm{O}_{2}$, comparing with incubation without $\mathrm{H}_{2} \mathrm{O}_{2} \quad(25 \mu \mathrm{M}$ : $379 \pm 13, \mathrm{p}=0.011 ; 50 \mu \mathrm{M}: 413 \pm 27, \mathrm{p}<0.001$ $100 \mu \mathrm{M}: 428 \pm 22, \quad \mathrm{p}<0.001 ; 200 \mu \mathrm{M}: 521 \pm 37$, $\mathrm{p}<0.001)$.

The effect of $\mathrm{H}_{2} \mathrm{O}_{2}$ on incubated spermatozoa is shown in Fig. 2 as effect sizes respect to the control at $2 \mathrm{~h}\left(0 \mu \mathrm{M} \mathrm{H}_{2} \mathrm{O}_{2}\right)$. In general, only the highest $\mathrm{H}_{2} \mathrm{O}_{2}$ concentration $(200 \mu \mathrm{M})$ showed an effect in this experiment. Total motility decreased with the incubation (from $36.6 \pm 5.7 \%$ to $28.6 \pm 8.4 \%$ at $2 \mathrm{~h} ; \mathrm{p}=0.031$ ) It did not decreased further with $\mathrm{H}_{2} \mathrm{O}_{2}$ (effect size not significant; Fig. 2a), except for $200 \mu \mathrm{M}$, which decreased motility down to $21.4 \pm 7.5 \% \quad(\mathrm{p}=0.037)$. While linearity changed neither with incubation nor with $\mathrm{H}_{2} \mathrm{O}_{2}$ treatments (Fig. 2c), velocity and ALH decreased after $2 \mathrm{~h}$ of incubation $(101.2 \pm 6.2-88.5 \pm 6.1 \mu \mathrm{m} / \mathrm{s}$ $\mathrm{p}<0.031 ; 4.1 \pm 0.2-3.6 \pm 0.2 \mu \mathrm{m}, \mathrm{p}<0.020)$. Their values when they were incubated with $200 \mu \mathrm{M} \mathrm{H}_{2} \mathrm{O}_{2}$ were $72.7 \pm 9.1 \mu \mathrm{m} / \mathrm{s}$ and $3.0 \pm 0.2 \mu \mathrm{m}(\mathrm{p}=0.020$
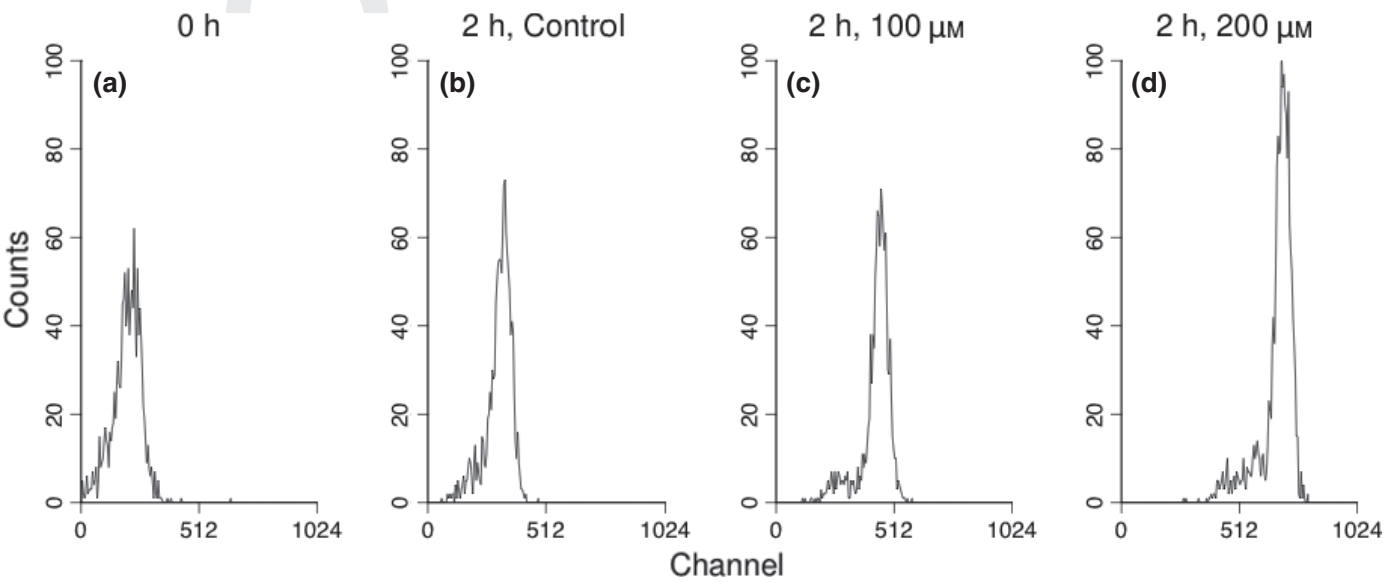

Fig. 1. Representative histograms from samples stained with CM- $\mathrm{H}_{2}$ DCFDA/TO-PRO-3, showing fluorescence intensity for CM- ${ }_{2}$ DCFDA in $\mathbf{6}$ the TO-PRO-1- subpopulation (viable spermatozoa). A higher fluorescence (given as fluorescence channel number, 1-1024) indicates higher intracellular reactive oxygen species. The mean fluorescence increased from baseline values at $0 \mathrm{~h}$ (a) to $2 \mathrm{~h}$ (b), and within $2 \mathrm{~h}$, with increasing $\mathrm{H}_{2} \mathrm{O}_{2}$ concentrations [100 $\mu \mathrm{M}(\mathrm{c})$ and $200 \mu \mathrm{M}(\mathrm{d})$ are shown here] 

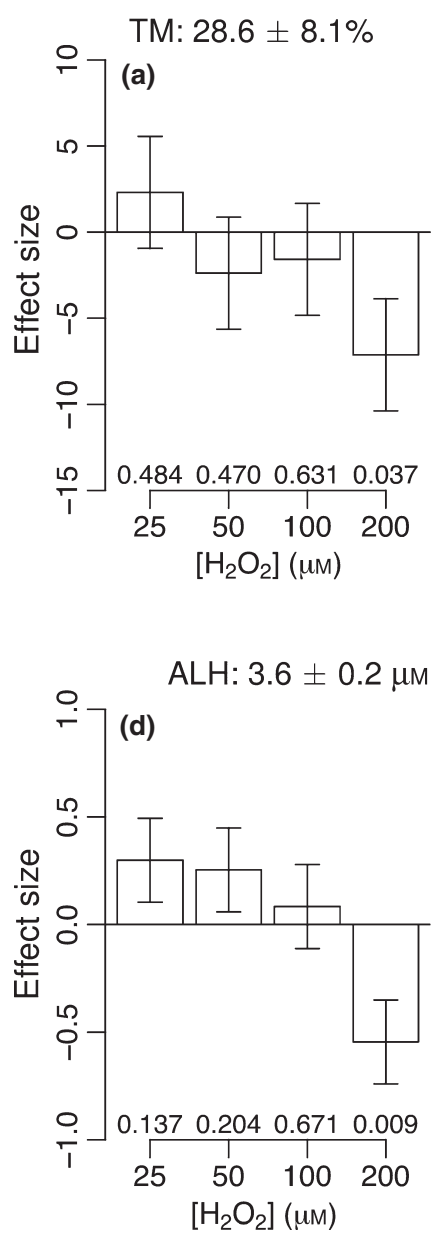

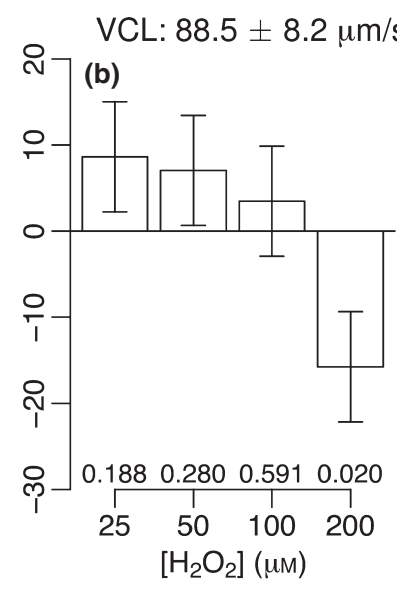

Viability: $23.4 \pm 5.8 \%$

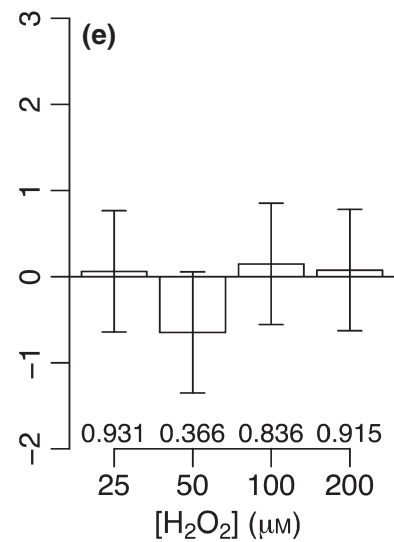

LIN: $30.8 \pm 1.4 \%$

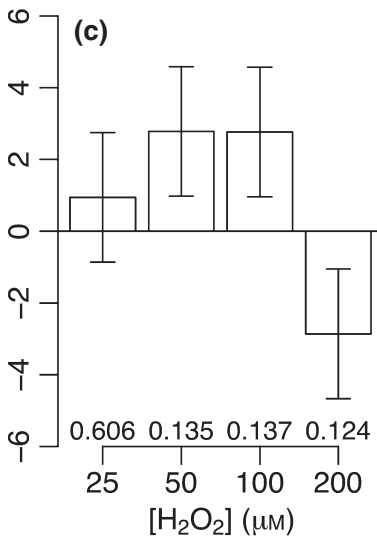

Apoptotic ratio:

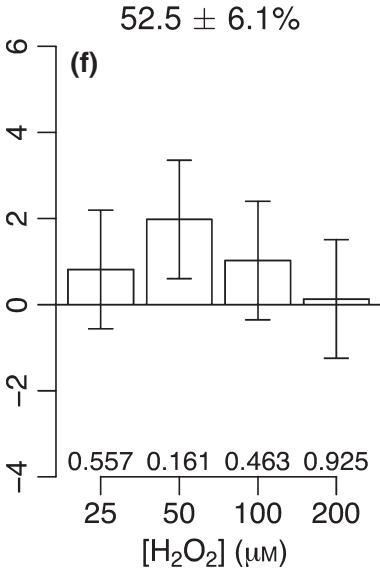

Fig. 2. Effect sizes of the $\mathrm{H}_{2} \mathrm{O}_{2}$ treatments, for the CASA analysis and YO-PRO-1/PI stain (viability and apoptotic ratio). In each case, the control value at $2 \mathrm{~h}\left(0 \mu \mathrm{M} \mathrm{H}_{2} \mathrm{O}_{2}\right)$ was used as the intercept of the model (mean \pm SEM showed), effect sizes being the relative variation of the parameter from the control value. For each $\mathrm{H}_{2} \mathrm{O}_{2}$ treatment, $\mathrm{p}$ values are given above the $x$-axis $\left(\mathrm{H}_{0}\right.$ : effect not different from 0$)$. Total motility (TM; a), curvilinear velocity (VCL; b) and the mean amplitude of the lateral movement of the head (ALH; d) were significantly reduced after $200 \mu \mathrm{M} \mathrm{H}_{2} \mathrm{O}_{2}$ treatment, whereas linearity (LIN; c), viability (e) and the apoptotic ratio (f) were not significantly affected by $\mathrm{H}_{2} \mathrm{O}_{2}$ addition

and $\mathrm{p}=0.009$, respectively), not changing significantly with other $\mathrm{H}_{2} \mathrm{O}_{2}$ treatments (Fig. 2b, d).

Incubation decreased the proportion of viable spermatozoa $(55.2 \pm 4.4-46.1 \pm 5.1 \% ; \mathrm{p}=0.018)$, tended to increase the apoptotic ratio (47.9 $\pm 5.3-$ $52.5 \pm 5.9 \% ; p=0.060)$ and slightly increased the lipid peroxidation of the samples, as estimated by the LPO by-product MDA, but not significantly (3.8 \pm $0.7 \mathrm{nmol}$ MDA $/ 10^{8}$ spermatozoa to $3.9 \pm 0.6 \mathrm{nmol}$ MDA $/ 10^{8}$ spermatozoa; $\mathrm{p}=0.051$ ). Addition of $\mathrm{H}_{2} \mathrm{O}_{2}$ did not modify the proportion of viable spermatozoa or the apoptotic ratio, comparing with $2-\mathrm{h}$ incubation without $\mathrm{H}_{2} \mathrm{O}_{2}$ (Fig. 2e, f). LPO levels did not increase in any $\mathrm{H}_{2} \mathrm{O}_{2}$ treatment comparing with the incubation without $\mathrm{H}_{2} \mathrm{O}_{2}$ (Fig. 3a); nevertheless, when comparing with the results at $0 \mathrm{~h}, 50 \mu \mathrm{M} \mathrm{H}_{2} \mathrm{O}_{2}$ and above significantly increased MDA concentration (effect sizes of $+0.4 \pm 0.1$ for $50 \mu \mathrm{M},+0.5 \pm 0.1$ for $100 \mu \mathrm{M}$ and $+0.4 \pm 0.1$ for $200 \mu \mathrm{M}$, indicating increases above the $0 \mathrm{~h}$ levels, $\mathrm{p}<0.05$; the effect size of 2 - $\mathrm{h}$ incubation without $\mathrm{H}_{2} \mathrm{O}_{2}$ was $+0.3 \pm 0.1, \mathrm{p}=0.051$ ).

The SCSA test revealed that incubation alone did not cause significant changes to chromatin stability ( $\%$ DFI: $4.9 \pm 1.5 \%$ at $0 \mathrm{~h}$ and $3.2 \pm 0.6 \%$ at $2 \mathrm{~h}, \mathrm{p}=0.353$;
HDS: $2.7 \pm 0.8 \%$ at $0 \mathrm{~h}$ and $4.1 \pm 1.3 \%$ at $2 \mathrm{~h}, \mathrm{p}=$ 0.198). Only $200 \mu \mathrm{M} \mathrm{H} \mathrm{H}_{2} \mathrm{O}_{2}$ increased \% DFI significantly, up to $10.3 \pm 2.9 \%$ (Fig. $3 \mathrm{~b}$ ), not having effect on $\operatorname{HDS}$ (Fig. 3c).

\section{Experiment 2. Individual male-to-male variation in response to oxidative stress}

In this experiment, we tested the effect of male-to-male variation during the incubation, including the response to oxidative stress caused by the higher dose of $\mathrm{H}_{2} \mathrm{O}_{2}$. In general, males differed at thawing ( $p<0.01$ for TM, VCL, ALH and viability). Three groups were differentiated (see group at $0 \mathrm{~h}$ in Fig. 4): males 1, 2 and 6 were characterized by higher motility (TM: $40.9 \pm 3.0 \%$; VCL: $104.7 \pm 5.3 \mu \mathrm{m} / \mathrm{s}$; ALH: $4.1 \pm$ $0.2 \mu \mathrm{m})$ and viability $(64.3 \pm 2.2 \%)$; males 3 and 4 were characterized by low motility (TM: $18.9 \pm 2.2 \%$; VCL: $66.7 \pm 6.5 \mu \mathrm{m} / \mathrm{s}$; ALH: $3.0 \pm 0.2 \mu \mathrm{m})$ while maintaining a relatively high viability $(54.1 \pm 2.4 \%)$; and males 5 and 7 were characterized by low motility (TM: $16.8 \pm 1.4 \%$ ), while maintaining high kinematic parameters (VCL: $94.9 \pm 2.0 \mu \mathrm{m} / \mathrm{s}$; ALH: $4.0 \pm$ $0.1 \mu \mathrm{m})$ and lower viability $(40.7 \pm 2.8 \%)$. 

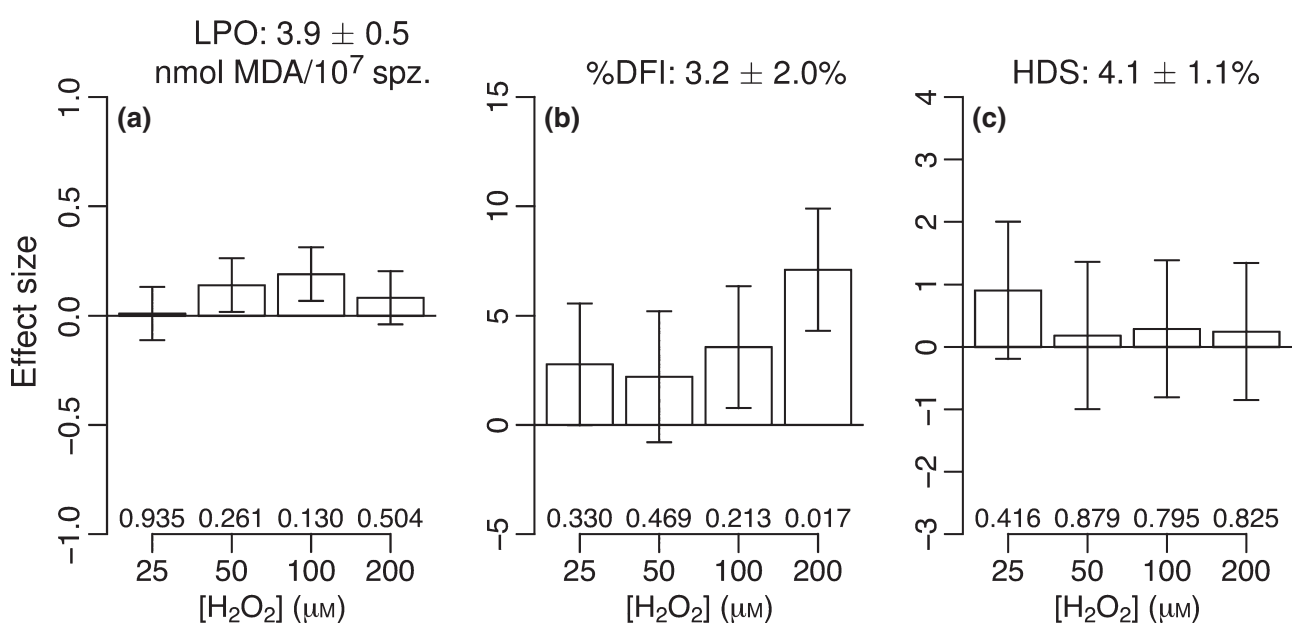

Fig. 3. Model effect sizes of the $\mathrm{H}_{2} \mathrm{O}_{2}$ treatments showed for the lipoperoxidation analysis (LPO) and sperm chromatin structure assay (DNA damage). In each case, the control value at $2 \mathrm{~h}\left(0 \mu \mathrm{M} \mathrm{H}_{2} \mathrm{O}_{2}\right)$ was used as the intercept of the model (mean \pm SEM showed), and the effect sizes are the relative variation of the parameter from the control value. For each $\mathrm{H}_{2} \mathrm{O}_{2}$ treatment, $\mathrm{p}$ values are given above the $x$-axis $\left(H_{0}\right.$ : effect not different from 0). Neither LPO (a) nor high DNA stainability (HDS; c) was significantly affected by the tested $\mathrm{H}_{2} \mathrm{O}_{2}$ concentrations, but the percentage of spermatozoa with high DNA fragmentation index ( $\%$ DFI; b) significantly increased after incubation with $200 \mu_{\mathrm{M}} \mathrm{H}_{2} \mathrm{O}_{2}$

Considering the whole experiment, male-to-male variability did not disappear after incubation with or without $\mathrm{H}_{2} \mathrm{O}_{2}$, but it was a significant factor for all studied parameters $(\mathrm{p}<0.001$ for TM, VCL, ALH and viability; $\mathrm{p}<0.01$ for apoptotic ratio; $\mathrm{p}<0.05$ for LIN and LPO). What is more important that variability affected how samples from different males responded to the incubation and oxidative stress (male \pm treatment interaction). We found that interaction significant for $\operatorname{VCL}\left(F_{12,27}=3.036, \mathrm{p}=0.007\right), \operatorname{LIN}\left(F_{12,27}=3.107\right.$, $\mathrm{p}=0.007)$ and ALH $\left(F_{12,27}=2.662, \quad \mathrm{p}=0.017\right)$. These differences throughout treatments can be appreciated in the interaction plots showed in the Fig. 4. It is clear that the behaviour of the samples was similar in the case of LPO and viability (Fig. 4e, f, change during incubation and little difference among 2 and $2 \mathrm{~h}$ plus $\mathrm{H}_{2} \mathrm{O}_{2}$ ), whereas most of the variability was shown in motility parameters. Total motility (Fig. 4a) suggested some degree of male-to-male variability on the response to treatments, but not reaching significance $\left(F_{12,27}=1.838, \mathrm{p}=0.092\right)$.

Therefore, most of the variability concerning treatment response was expressed on the kinematic parameters. For VCL (Fig. 4b), males 1, 3 and 5 underwent little change after incubation, but dropped if $\mathrm{H}_{2} \mathrm{O}_{2}$ was included in the medium, whereas males 2, 6 and 7 were affected by incubation without $\mathrm{H}_{2} \mathrm{O}_{2}$ (and in a higher degree, specially for 6 , in presence of $\mathrm{H}_{2} \mathrm{O}_{2}$ ), and male 4 was little affected by the treatments. A similar pattern was detected for ALH (Fig. 4d). For LIN (Fig. 4c), a different grouping developed. In a first group (males 2, 4 and 5), LIN was little affected by incubation or oxidative stress. Contrarily, LIN dropped during incubation in the samples of males 6 and 7, whereas it did not decrease during incubation in the samples of 1 and 3 (in fact, increased for 3), but decreased (considerably for 1) in presence of $\mathrm{H}_{2} \mathrm{O}_{2}$.

A principal component analysis of averaged results for each male and treatment allowed to show these results in the bidimensional space defined by the first two principal components extracted (Fig. 5a). The male- to-male variability (initial characteristics, after incubation characteristics - either in presence or in absence of $\mathrm{H}_{2} \mathrm{O}_{2}$ - and the response to the treatments) is displayed in the Fig. 5b. In that plot it is made clear that samples from different males behaved differently, as showed by the different directions and lengths of the vectors joining the points for each sample. According to the direction of change after incubation without $\mathrm{H}_{2} \mathrm{O}_{2}$, males could be grouped in three groups: one grouping males 1 and 3 , other with males 2 and 7 and a third one with males 4,5 and 6. When $\mathrm{H}_{2} \mathrm{O}_{2}$ was included, male 2 was just affected by the effect size, while maintaining the same direction. Others showed a different response (males 4, 5 and 7), but only in one or two parameters and not too large; male 6 could be included in this group, although the differences were much larger for that male. Finally, males 1, 3 showed a dramatically different response if incubated in absence or presence of $\mathrm{H}_{2} \mathrm{O}_{2}$.

\section{Discussion}

Oxidative stress has an important role in sperm physiology. In this study, we have studied this topic on cryopreserved epididymal spermatozoa; therefore, we must to point out that results might be different in fresh or ejaculated doses. Cryopreservation not only reduces sperm quality, but also induces oxidative stress and decreases the antioxidants in semen (Aisen et al. 2005; Peris et al. 2007), and epididymal spermatozoa have not contacted with seminal plasma, which contributes to the antioxidant defence of semen. Furthermore, maleto-male variability also affects to the resistance to cryopreservation-derived damage (Esteso et al. 2006; Loomis and Graham 2008), possibly enhancing postthawing differences among males. These facts were considered when planning this study, and therefore our analysis and conclusions are within the context of cryopreserved epididymal spermatozoa.

In a previous study on oxidative agents of our own group (Martinez-Pastor et al. 2009a), it was found that $10 \mu \mathrm{M} \mathrm{H}_{2} \mathrm{O}_{2}$ did not affect thawed spermatozoa, but 

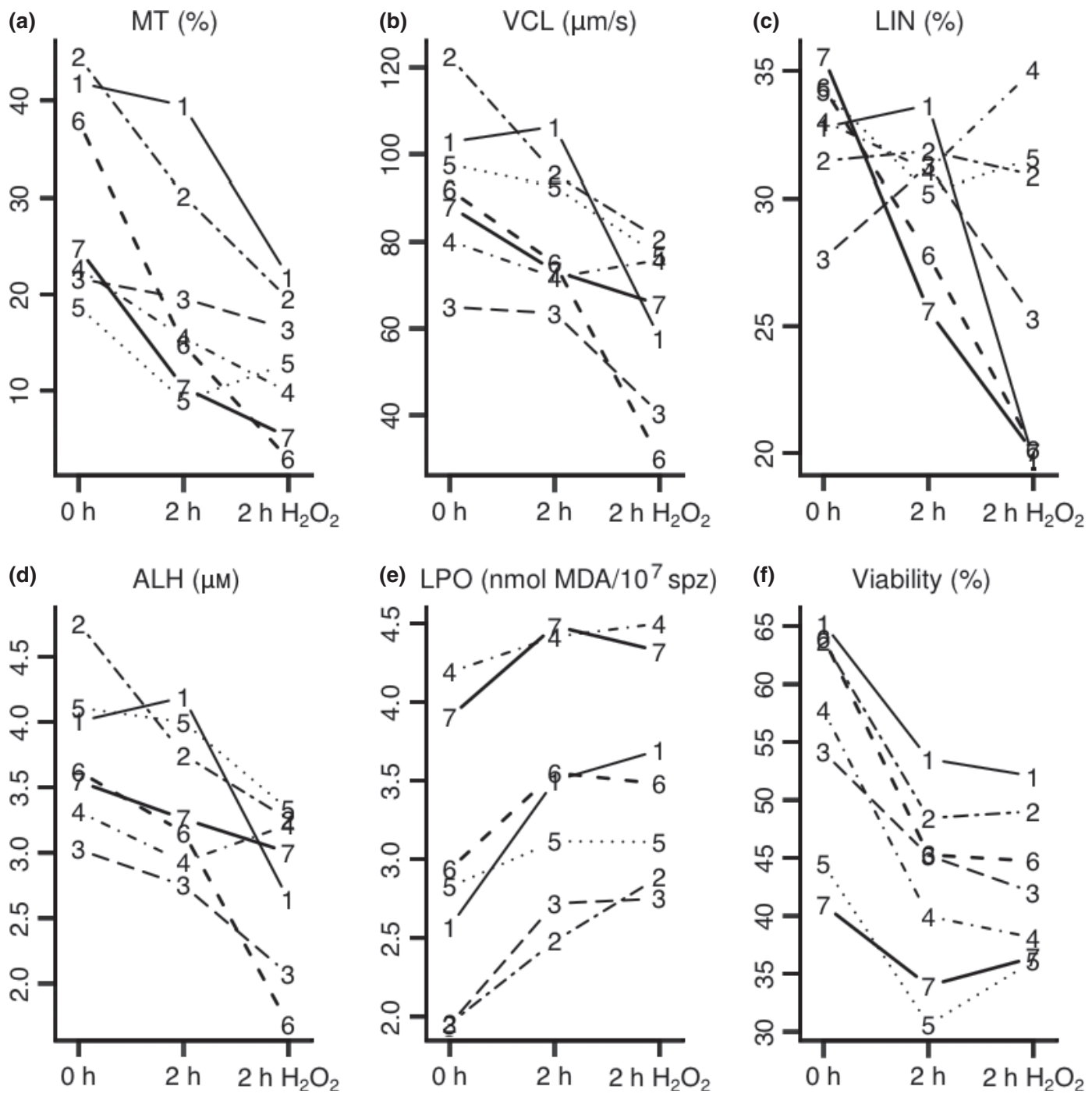

Fig. 4. These interaction plots show the effect of the individual males (1-7) and treatments $(0,2 \mathrm{~h}$ incubation and $2 \mathrm{~h}$ incubation with $200 \mu \mathrm{M}$ $\mathrm{H}_{2} \mathrm{O}_{2}$ ) on sperm parameters (mean values displayed). Lines do not imply a continuity among $2 \mathrm{~h}$ incubation and $2 \mathrm{~h}$ incubation plus $200 \mu \mathrm{M}$ $\mathrm{H}_{2} \mathrm{O}_{2}$, but they are used to highlight the different values and changes, among the treatments, of samples from different males. Differences among males are evident for motility parameters, while male-to-male differences (regarding different behaviour among treatments) were minimal for LPO and viability

$100 \mu \mathrm{M}$ and $1 \mathrm{~mm}$ depressed motility within $1 \mathrm{~h}$ of incubation (in fact, $1 \mathrm{~mm}$ abolished sperm motility almost immediately after adding it to the sample). We determined that a similar effect of xanthine oxidase/hypoxanthine was in fact caused by $\mathrm{H}_{2} \mathrm{O}_{2}$ generation. In our study, the only significant effects of $\mathrm{H}_{2} \mathrm{O}_{2}$ were caused by $200 \mu \mathrm{M}$, not by $100 \mu \mathrm{M}$. Apart from some differences on the experimental design (Dominguez-Rebolledo et al. 2009), it is possible that the limit above which $\mathrm{H}_{2} \mathrm{O}_{2}$ causes a detectable effect (regarding our experimental tests) would lay in the order of magnitude of $10^{-4} \mathrm{M}$. Individual males might present a different sensitivity to $\mathrm{H}_{2} \mathrm{O}_{2}$ within that order of magnitude, as suggested by the male-to-male variability experiment. In our previous study, we used samples from other set of males, which could be the source of the observed differences.

Although addition of $\mathrm{H}_{2} \mathrm{O}_{2}$ increased intracellular ROS, no other effects were observed below $200 \mu \mathrm{M}$. We found that even $10 \mu \mathrm{M} \mathrm{H}_{2} \mathrm{O}_{2}$ could increase intracellular
ROS above control (Martinez-Pastor et al. 2009a), but this increase did not result in a noticeable change of motility or sperm physiology. However, Peris et al. (2007), working with fresh ram sperm, found that $50 \mu \mathrm{M}$ $\mathrm{H}_{2} \mathrm{O}_{2}$ decreased motility in only $1 \mathrm{~h}$ of incubation. Nevertheless, these authors did not observe capacitation-related changes (chlortetracycline stain) among different $\mathrm{H}_{2} \mathrm{O}_{2}$ concentrations $(0,50$ and $150 \mu \mathrm{M})$, except for $300 \mu \mathrm{M}$, which caused a significant increase in acrosome-reacted spermatozoa at $1 \mathrm{~h}$ of incubation (but not after 4 or $24 \mathrm{~h}$ ). In the present study, $\mathrm{H}_{2} \mathrm{O}_{2}$ did not induce changes in the apoptotic ratio of the samples, a parameter depending on YO-PRO-1 stain, putatively related to membrane condition and possibly connected to the physiological status of the sperm cell (Peña et al. 2007; Martinez-Pastor et al. 2008). Previous studies have highlighted the role of ROS on the modulation of sperm physiology and their role activating capacitation (O'Flaherty et al. 1999; Baumber et al. 2003; Awda et al. 2009). For instance, Roy and Atreja 

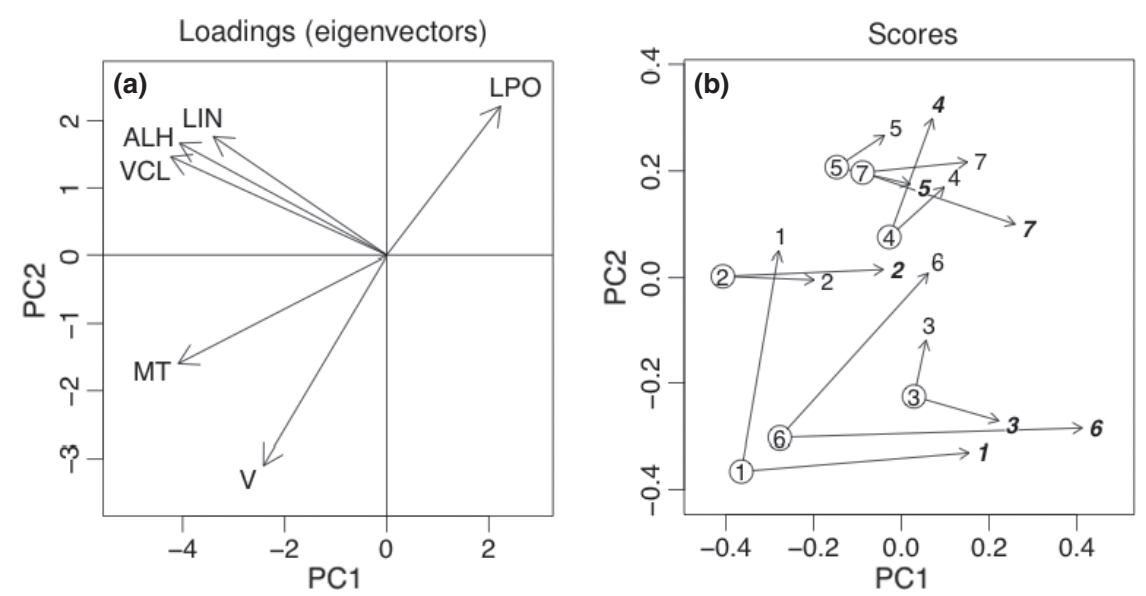

Fig. 5. Representation of the multivariate data showed in Fig. 4 in the bidimensional space resulting from performing a principal component $\mathbf{8}$ analysis (PCA) with total motility, VCL, LIN, ALH, viability (V) and LPO (the first two principal components, PC1 and PC2, were selected). Subfigure (a) shows the variable loadings (linear relationships among the principal components and the variables), represented by the six eigenvectors, to help to interpret subfigure (b): for instance, in subfigure (b), samples 'moving' towards the lower-right quadrant would indicate samples with decreasing kinematic parameters, while those 'moving' towards the upper-right quadrant would have decreasing motility and viability, while increasing LPO. Subfigure (b) presents the changes underwent by samples from different males (1-7) as translations throughout the PC coordinates. Samples at $0 \mathrm{~h}$ are represented by circled numbers, which are the starting point for vectors representing the change underwent by these samples after $2 \mathrm{~h}$ of incubation (plain numbers) or $2 \mathrm{~h}$ of incubation with $200 \mu \mathrm{M}$ of $\mathrm{H}_{2} \mathrm{O}_{2}$ (italic-bold numbers). The male-to-male differences showed in Fig. 4, regarding treatment effects, are evident in this plot

(2008) induced capacitation and associated tyrosine phosphorylation in buffalo spermatozoa by incubating with $50 \mu \mathrm{M} \quad \mathrm{H}_{2} \mathrm{O}_{2}$. More detailed studies, such as analysis of tyrosine phosphorylation of specific proteins, should be performed in small ruminants, to determine whether $\mathrm{H}_{2} \mathrm{O}_{2}$ induces physiological changes beyond those reported by Peris et al. (2007) and us. The detection of these changes is of capital importance, since they might be unnoticed, affecting sperm functionality farther in sperm work protocols.

Agreeing with previous studies (Aitken et al. 1993; Armstrong et al. 1999; Peris et al. 2007; MartinezPastor et al. 2009a), sperm motility was the most sensitive parameter to $\mathrm{H}_{2} \mathrm{O}_{2}$. Motility loss by $\mathrm{H}_{2} \mathrm{O}_{2}$ has been primarily attributed to the inactivation of glycolytic enzymes, leading to energetic draining in the flagellum (Armstrong et al. 1999; Baumber et al. 2000). However, the sensitivity of spermatozoa to $\mathrm{H}_{2} \mathrm{O}_{2}$ varies dramatically among studies. Ramos and Wetzels (2001) found an almost total loss of motility after incubating

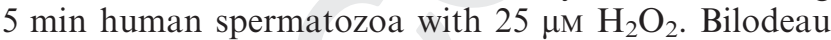
et al. (2002), testing a wide range of $\mathrm{H}_{2} \mathrm{O}_{2}$ concentrations on bovine semen, found that $75 \mu \mathrm{M}$ of $\mathrm{H}_{2} \mathrm{O}_{2}$ immediately decreased sperm motility and that just $12.5 \mu \mathrm{M} \mathrm{H}_{2} \mathrm{O}_{2}$ decreased motility after $1 \mathrm{~h}$ of incubation. This might imply that small ruminant spermatozoa might be more resilient to this effect, as we suggested in a previous study (Martinez-Pastor et al. 2009a).

A non-significant increase in MDA with time was observed, which seemed to be accelerated by $\mathrm{H}_{2} \mathrm{O}_{2}$ presence. This increase in LPO was unrelated to motility changes. These observations suggest that red deer sperm might be little prone to $\mathrm{H}_{2} \mathrm{O}_{2}$-induced lipoperoxidation. Peris et al. (2007) did not found increasing LPO levels when submitting the samples to $\mathrm{H}_{2} \mathrm{O}_{2}$ levels up to $300 \mu \mathrm{M}$, but after incubating their samples for $24 \mathrm{~h}$. However, these authors found correlations among
MDA concentration and other sperm parameters, which were not noticed in our study. It seems that there are between-species differences regarding susceptibility and consequences of lipid peroxidation. For instance, Alvarez and Storey (1989) could increase LPO and loss of motility in human and mouse sperm by adding $\mathrm{H}_{2} \mathrm{O}_{2}(1$ and $5 \mathrm{~mm}$ ), whereas the same concentrations of $\mathrm{H}_{2} \mathrm{O}_{2}$ were insufficient to induce LPO in rabbit sperm. Similarly, we could detect an increase in LPO using the TBARS technique in deer spermatozoa after incubating with $1 \mathrm{mM} \mathrm{H}_{2} \mathrm{O}_{2}$, but we could not detect a significant increase when applying $100 \mu \mathrm{M} \quad \mathrm{H}_{2} \mathrm{O}_{2}$ (Dominguez-Rebolledo et al. 2010a,b).

Subjecting thawed spermatozoa to oxidative stress can affect chromatin integrity, and the SCSA test can be used to detect it (Fernandez-Santos et al. 2009; Martinez-Pastor et al. 2009b). Sperm chromatin integrity was affected by $200 \mu \mathrm{M} \mathrm{H} \mathrm{H}_{2} \mathrm{O}_{2}$. Previously (Martinez-Pastor et al. 2009a), we could not identify such chromatin insult, possibly because of the different set of males used. Again, it is possible that individual sample quality (different stocks of semen doses) could have a role, although we cannot discard variations in the experimental protocol (lack of sperm washing in our previous study). In fact, we found that washed samples were more vulnerable to oxidative stress than unwashed ones (Dominguez-Rebolledo et al. 2009). Other studies have shown apparently lower chromatin damage susceptibility in similar species. For instance, Peris et al. (2007) reported that SCSA showed that 150 and $300 \mu \mathrm{M} \mathrm{H}_{2} \mathrm{O}_{2}$ increased the \% DFI on ram spermatozoa, but only after 24 -h incubation. In human spermatozoa, Ramos and Wetzels (2001) did not detect DNA damage when sperm from normospermic men were incubated for $1 \mathrm{~h}$ in the presence of $25 \mu \mathrm{M}$ of $\mathrm{H}_{2} \mathrm{O}_{2}$, but damage was observed after $24 \mathrm{~h}$ (using TUNEL), alerting that low levels of ROS can be damaging given long incubation 
times. Another study (Hughes et al. 1996), using the COMET assay, showed that applying 100 and $200 \mu \mathrm{M}$ $\mathrm{H}_{2} \mathrm{O}_{2}$ for only one hour caused an important increase in DNA damage and that only $40 \mu \mathrm{M} \mathrm{H}_{2} \mathrm{O}_{2}$ was required to cause a small increase in DNA damage in asthenozoospermic samples (although baseline levels were similar to those of normozoospermic samples). This study highlights the importance of previous susceptibility to oxidative stress and the importance of between sample heterogeneity, regarding ROS resistance.

In the second part of our study, we aimed at studying the male-to-male variability on the response to $\mathrm{H}_{2} \mathrm{O}_{2}$. Although we worked with a limited number of males, it was evident that male-to-male variability had an effect, not only regarding the resilience to oxidative stress, but also to incubation without oxidants. In other studies, we have reported that sperm male-to-male variability seems to be high in red deer, possibly because of the unselected nature of the populations from which we obtained our samples (Garde et al. 2006). In fact, working with those wild populations allows us to easily detect and study male-to-male variability, which would be harder to detect working with animals submitted to strong human selection. We have previously showed that red deer present evident male-to-male differences in sperm characteristics and fertility (Malo et al. 2005) and in sperm sensitivity to cryopreservation (Soler et al. 2003). Moreover, we have proposed that variability could even reflect in biased sex ratios, depending on the fertility of different males (Gomendio et al. 2006).

In the present study, motility parameters were affected by incubation in some males, whereas in others motility was maintained almost unaltered for the duration of incubation, being only affected if oxidative stress was present. Contrarily, although individual variability was evident considering initial MDA concentration and sperm viability, it did not affect the changes on these variables after incubation with or without oxidative stress. It is known that many factors can affect membrane composition, among them individual variability, and that its composition influences its resistance and susceptibility to oxidative stress (Lenzi et al. 2002). It is possible that the small increase in LPO observed after incubation and $\mathrm{H}_{2} \mathrm{O}_{2}$ might have prevented us from detecting the interaction among males and treatments. Another reason could be that the high dilution and the freezing-thawing of the cryopreserved samples would have dimmed membrane-related differences, a hypothesis that could be tested in another study using fresh spermatozoa. It is important to consider that in vivo studies (Reglero et al. 2009) have shown no differences on LPO between deer living in areas contaminated with heavy metals and other living in uncontaminated areas, but the same study found differences among deer living in different estates. These findings suggest that some oxidative stress markers, such as LPO, could indeed depend more on the male than on environmental stressors.

Motility can be affected by multiple factors; and therefore, it is a good candidate to detect variability among males or samples (Malo et al. 2005). The resistance of sperm samples to incubation was apparently not dependent on their initial quality. Thus, male 1 and 6 had similar initial motility, but whereas male 1 maintained the same motility after incubation, and it was halved when $\mathrm{H}_{2} \mathrm{O}_{2}$ was present, it dropped dramatically for male 6 , and it was abolished by $\mathrm{H}_{2} \mathrm{O}_{2}$. This example not only shows the impact of between-male differences, but also that the initial quality of a sample (just after thawing, in this case) might be not informative of its real potentiality. Therefore, sperm 'freezability' (comparison of the pre-freezing and post-thawing quality) might not suffice when characterizing samples from a male in the laboratory, being necessary to test the real resistance of spermatozoa by challenging them in physiological and non-physiological conditions (Roth et al. 1999; Soler et al. 2008). Furthermore, molecular techniques may be used to predict the performance of spermatozoa beyond cryopreservation (Thurston et al. 2002; Grunewald et al. 2008).

In summary, we conclude that oxidative stress caused by $\mathrm{H}_{2} \mathrm{O}_{2}$ clearly affected kinematic parameters of cryopreserved red deer spermatozoa, but only at relatively high concentrations (considering previous studies, at a magnitude of $10^{-4} \mathrm{M}$ ). It did not seem to influence sperm viability or apoptotic markers (as defined with YO-PRO-1). This may be a consequence of membrane resilience to oxidative stress, but also to the effect of cryopreservation, which might have already removed susceptible spermatozoa from the samples. We have to point out that we utilized only epididymal spermatozoa and that results might vary when using ejaculated samples. In a previous study on red deer (MartínezPastor et al. 2006), we found that cryopreservation conditions of epididymal and ejaculated samples might vary. These differences could also affect the response of oxidative stress of ejaculated samples.

In conclusion, cryopreservation of gametes and embryos and the development of Genetic Resource Banks allow us to have a gene resource for an indefinite time (Watson and Holt 2001). These assisted reproductive technologies (ART) are potentially capable of improving the propagation and conservation of wild and endangered species (Wildt et al. 1997). Of the genetic material in cryobanks, the collection, storage and subsequent use of spermatozoa has found the most widespread application (Watson and Holt 2001). According to this, cryopreservation of spermatozoa combined with artificial insemination (AI) has been the method of ART that has been most extensively applied to deer species (Asher et al. 2000; Garde et al. 2006). In the present work, male-to-male variability was evident in the response to incubation both with and without $\mathrm{H}_{2} \mathrm{O}_{2}$. This male-to-male variability is important, because it reflects on fertility and in the outcome of other artificial reproductive techniques (AI and IVF $\mathbf{3}$ success). Thus, we must discriminate among samples from different males not only according to their 'freezability', but also according to their performance after thawing and in stressing situations. We must take into account these differences as much to improve freezing protocols as in the post-thawing protocols, considering protective agents such as antioxidants and adjusting them to the characteristics of different kinds of samples. This is especially important when dealing with valuable specimens of endangered animals, which is 
usual working with wild species. Actually, there is a remarkable interest in the use of ART for the management of Iberian deer (C. elaphus hispanicus) populations. Specifically, ART may play an important role for the purpose of ensuring genetic preservation and/or genetic progress. Moreover, the results of the present work can contribute to the development of adequate protocols for red deer as a farming species and also for other small ruminants.

\section{Acknowledgements}

This work has been supported by the Spanish Ministry of Education and Science (Project AGL2004-05904/GAN) and by the Junta de Comunidades de Castilla-La Mancha (Project PAC06-0047). A.E Domínguez-Rebolledo was supported by Consejo Nacional de Ciencia y Tecnología (CONACyT), México. Rocío Fernández Santos and Felipe Martínez-Pastor were supported by the Juan de la Cierva and Ramón y Cajal programs (Ministerio de Ciencia y Tecnología, Spain), respectively. We thank Enrique Del Olmo for helping in field work and cytometry analyses.

\section{Conflict of interest}

$4 \mathrm{Xxxxx}$

\section{Author contributions}

All authors have contributed to the work, from experimental design to writing the manuscript.

\section{References}

Agarwal A, Saleh RA, 2002: Role of oxidants in male infertility: rationale, significance, and treatment. Urol Clin North Am 29, 817-827.

Aisen E, Quintana M, Medina V, Morello H, Venturino A, 2005: Ultramicroscopic and biochemical changes in ram spermatozoa cryopreserved with trehalose-based hypertonic extenders. Cryobiology 50, 239-249.

Aitken RJ, Buckingham D, Harkiss D, 1993: Use of a xanthine oxidase free radical generating system to investigate the cytotoxic effects of reactive oxygen species on human spermatozoa. J Reprod Fertil 97, 441-450.

Aitken RJ, Paterson M, Fisher H, Buckingham DW, Van DM, 1995: Redox regulation of tyrosine phosphorylation in human spermatozoa and its role in the control of human sperm function. J Cell Sci 108(Pt 5), 2017-2025.

Alvarez JG, Storey BT, 1989: Role of glutathione peroxidase in protecting mammalian spermatozoa from loss of motility caused by spontaneous lipid peroxidation. Gamete Res $\mathbf{2 3}$ $77-90$.

Armstrong JS, Rajasekaran M, Chamulitrat W, Gatti P, Hellstrom WJ, Sikka SC, 1999: Characterization of reactive oxygen species induced effects on human spermatozoa movement and energy metabolism. Free Radic Biol Med 26, 869-880.

Asher GW, Berg DK, Evans G, 2000: Storage of semen and artificial insemination in deer. Anim Reprod Sci 62, 195211.

Awda BJ, Kenzie-Bell M, Buhr MM, 2009: Reactive oxygen species and boar sperm function. Biol Reprod 81, 553-561.

Baumber J, Ball BA, Gravance CG, Medina V, Vies-Morel MC, 2000: The effect of reactive oxygen species on equine sperm motility, viability, acrosomal integrity, mitochondrial membrane potential, and membrane lipid peroxidation. J Androl 21, 895-902.
Baumber J, Sabeur K, Vo A, Ball BA, 2003: Reactive oxygen species promote tyrosine phosphorylation and capacitation in equine spermatozoa. Theriogenology 60, 1239-1247.

Bilodeau JF, Blanchette S, Cormier N, Sirard MA, 2002: Reactive oxygen species-mediated loss of bovine sperm motility in egg yolk Tris extender: protection by pyruvate, metal chelators and bovine liver or oviductal fluid catalase. Theriogenology 57, 1105-1122.

Castellanos P, Reglero MM, Taggart MA, Mateo R, 2010: Changes in fatty acid profiles in testis and spermatozoa of red deer exposed to metal pollution. Reprod Toxicol 29, 346-352.

Chen H, Chow PH, Cheng SK, Cheung AL, Cheng LY, WS O, 2003: Male genital tract antioxidant enzymes: their source, function in the female, and ability to preserve sperm DNA integrity in the golden hamster. J Androl 24, 704-711.

De Lamirade E, Gagnon C, 1994: Reactive oxygen species (ROS) and reproduction. Adv Exp Med Biol 366, 185-197.

Dominguez-Rebolledo AE, Fernandez-Santos MR, GarciaAlvarez O, Maroto-Morales A, Garde JJ, Martinez-Pastor F, 2009: Washing increases the susceptibility to exogenous oxidative stress in red deer spermatozoa. Theriogenology $\mathbf{7 2}$, 1073-1084.

Dominguez-Rebolledo AE, Martinez-Pastor F, FernandezSantos MR, Del Olmo E, Bisbal A, Ros-Santaella JL, Garde JJ, 2010a: Comparison of the TBARS assay and BODIPY $\mathrm{C}(11)$ probes for assessing lipid peroxidation in red deer spermatozoa (doi: 10.1111/j.1439-0531.2009.01578.x).

Dominguez-Rebolledo AE, Fernandez-Santos MR, Bisbal A, Ros-Santaella JL, Ramón M, Carmona M, Martinez-Pastor F, Garde JJ, 2010b: Improving the effect of incubation and oxidative stress on thawed spermatozoa from red deer by using different antioxidant treatments. Reprod Fertil Dev 22, 856-870.

Esteso MC, Fernandez-Santos MR, Soler AJ, Montoro V, Quintero-Moreno A, Garde JJ, 2006: The effects of cryopreservation on the morphometric dimensions of Iberian red deer (Cervus elaphus hispanicus) epididymal sperm heads. Reprod Domest Anim 41, 241-246.

Evenson DP, Darzynkiewicz Z, Melamed MR, 1980: Relation of mammalian sperm chromatin heterogeneity to fertility. Science 210, 1131-1133.

Fernandez-Santos MR, Esteso MC, Montoro V, Soler AJ, Garde JJ, 2006: Cryopreservation of Iberian red deer (Cervus elaphus hispanicus) epididymal spermatozoa: effects of egg yolk, glycerol and cooling rate. Theriogenology $\mathbf{6 6}$, 1931-1942.

Fernandez-Santos MR, Dominguez-Rebolledo AE, Esteso MC, Garde JJ, Martinez-Pastor F, 2009: Catalase supplementation on thawed bull spermatozoa abolishes the detrimental effect of oxidative stress on motility and DNA integrity. Int J Androl 32, 353-359.

Garde JJ, Martinez-Pastor F, Gomendio M, Malo AF, Soler AJ, Fernandez-Santos MR, Esteso MC, Garcia AJ, Anel L, Roldan ER, 2006: The application of reproductive technologies to natural populations of red deer. Reprod Domest Anim 41(Suppl 2), 93-102.

Gomendio M, Malo AF, Soler AJ, Fernandez-Santos MR, Esteso MC, Garcia AJ, Roldan ER, Garde J, 2006: Male fertility and sex ratio at birth in red deer. Science 314, 14451447.

Griveau JF, Renard P, Le LD, 1995: Superoxide anion production by human spermatozoa as a part of the ionophore-induced acrosome reaction process. Int J Androl 18, 67-74.

Grunewald S, Said TM, Paasch U, Glander HJ, Agarwal A, 2008: Relationship between sperm apoptosis signalling and oocyte penetration capacity. Int J Androl 31, 325-330. 
Hsu PC, Hsu CC, Guo YL, 1999: Hydrogen peroxide induces premature acrosome reaction in rat sperm and reduces their penetration of the zona pellucida. Toxicology 139, 93-101.

Hughes CM, Lewis SE, Kelvey-Martin VJ, Thompson W, 1996: A comparison of baseline and induced DNA damage in human spermatozoa from fertile and infertile men, using a modified comet assay. Mol Hum Reprod 2, 613-619.

Lenzi A, Gandini L, Lombardo F, Picardo M, Maresca V, Panfili E, Tramer F, Boitani C, Dondero F, 2002: Polyunsaturated fatty acids of germ cell membranes, glutathione and blutathione-dependent enzyme-PHGPx: from basic to clinic. Contraception 65, 301-304.

Loomis PR, Graham JK, 2008: Commercial semen freezing: individual male variation in cryosurvival and the response of stallion sperm to customized freezing protocols. Anim Reprod Sci 105, 119-128.

Malo AF, Garde JJ, Soler AJ, Garcia AJ, Gomendio M, Roldan ER, 2005: Male fertility in natural populations of red deer is determined by sperm velocity and the proportion of normal spermatozoa. Biol Reprod 72, 822-829.

Martinez-Pastor F, Fernandez-Santos MR, Del Olmo E, Dominguez-Rebolledo AE, Esteso MC, Montoro V, Garde JJ, 2008: Mitochondrial activity and forward scatter vary in necrotic, apoptotic and membrane-intact spermatozoan subpopulations. Reprod Fertil Dev 20, 547-556.

Martinez-Pastor F, Aisen E, Fernandez-Santos MR, Esteso MC, Maroto-Morales A, Garcia-Alvarez O, Garde JJ, 2009a: Reactive oxygen species generators affect quality parameters and apoptosis markers differently in red deer spermatozoa. Reproduction 137, 225-235.

Martinez-Pastor F, Fernández-Santos MR, DominguezRebolledo AE, Esteso MC, Garde JJ, 2009b: DNA status on thawed semen from fighting bull: a comparison between the SCD and the SCSA tests. Reprod Domest Anim 44, 424-431.

Martínez-Pastor F, Martínez F, García-Macías V, Esteso MC, Anel E, Fernández-Santos MR, Soler AJ, De PazP, Garde JJ, Anel L, 2006: A pilot study on post-thawing quality of Iberian red deer spermatozoa (epididymal and electroejaculated) depending on glycerol concentration and extender osmolality. Theriogenology 66, 1165-1172.

Oehninger S, Blackmore P, Mahony M, Hodgen G, 1995: Effects of hydrogen peroxide on human spermatozoa. J Assist Reprod Genet 12, 41-47.

O'Flaherty CM, Beorlegui NB, Beconi MT, 1999: Reactive oxygen species requirements for bovine sperm capacitation and acrosome reaction. Theriogenology 52, 289-301.

Ohkawa H, Ohishi N, Yagi K, 1979: Assay for lipid peroxides in animal tissues by thiobarbituric acid reaction. Anal Biochem 95, 351-358.

Ollero M, Gil-Guzman E, Lopez MC, Sharma RK, Agarwal A, Larson K, Evenson D, Thomas AJ Jr, Alvarez JG, 2001: Characterization of subsets of human spermatozoa at different stages of maturation: implications in the diagnosis and treatment of male infertility. Hum Reprod 16, 19121921.

Peña FJ, Saravia F, Johannisson A, Wallgren M, RodriguezMartinez H, 2007: Detection of early changes in sperm membrane integrity pre-freezing can estimate post-thaw quality of boar spermatozoa. Anim Reprod Sci 97, 74-83.

Peris SI, Bilodeau JF, Dufour M, Bailey JL, 2007: Impact of cryopreservation and reactive oxygen species on DNA integrity, lipid peroxidation, and functional parameters in ram sperm. Mol Reprod Dev 74, 878-892.

Ramos L, Wetzels AM, 2001: Low rates of DNA fragmentation in selected motile human spermatozoa assessed by the TUNEL assay. Hum Reprod 16, 1703-1707.

Reglero MM, Taggart MA, Castellanos P, Mateo R, 2009: Reduced sperm quality in relation to oxidative stress in red deer from a lead mining area. Environ Pollut 157, 22092215.

Rivlin J, Mendel J, Rubinstein S, Etkovitz N, Breitbart H, 2004: Role of hydrogen peroxide in sperm capacitation and acrosome reaction. Biol Reprod 70, 518-522.

Roth TL, Bush LM, Wildt DE, Weiss RB, 1999: Scimitar-horned oryx (Oryx dammah) spermatozoa are functionally competent in a heterologous bovine in vitro fertilization system after cryopreservation on dry ice, in a dry shipper, or over liquid nitrogen vapor. Biol Reprod 60, 493-498.

Roy SC, Atreja SK, 2008: Effect of reactive oxygen species on capacitation and associated protein tyrosine phosphorylation in buffalo (Bubalus bubalis) spermatozoa. Anim Reprod Sci 107, 68-84.

Sharma RK, Said T, Agarwal A, 2004: Sperm DNA damage and its clinical relevance in assessing reproductive outcome. Asian J Androl 6, 139-148.

Soler AJ, Garde JJ, 2003: Relationship between the characteristics of epididymal red deer spermatozoa and penetrability into zona-free hamster ova. J Androl 24, 393-400.

Soler AJ, Garcia AJ, Fernandez-Santos MR, Esteso MC, Garde JJ, 2003: Effects of thawing procedure on postthawed in vitro viability and in vivo fertility of red deer epididymal spermatozoa cryopreserved at -196 degrees C. J Androl 24, 746-756.

Soler AJ, Poulin N, Fernandez-Santos MR, Cognie Y, Esteso MC, Garde JJ, Mermillod P, 2008: Heterologous in vitro fertility evaluation of cryopreserved Iberian red deer epididymal spermatozoa with zona-intact sheep oocytes and its relationship with the characteristics of thawed spermatozoa. Reprod Domest Anim 43, 293-298.

Thurston LM, Siggins K, Mileham AJ, Watson PF, Holt WV, 2002: Identification of amplified restriction fragment length polymorphism markers linked to genes controlling boar sperm viability following cryopreservation. Biol Reprod 66, 545-554.

Waterhouse KE, Hofmo PO, Tverdal A, Miller RR Jr, 2006: Within and between breed differences in freezing tolerance and plasma membrane fatty acid composition of boar sperm. Reproduction 131, 887-894.

Watson PF, Holt WV, 2001: Organizational issues concerning the establishment of a genetic resource bank. In: Watson PF, Holt WV (eds), Cryobanking the Genetic Resource. Wildlife Conservation the Future? Taylor \& Francis, London, pp. 86-112.

Wildt DE, Rall WF, Critser JK, Monfort SL, Seal US, 1997: Genome resource banks: 'Live collection' for biodiversity conservation. Bioscience 47, 689-698.

Submitted: 25 May 2010; Accepted: 21 Jun 2010

Author's address (for correspondence): Dr Fernández-Santos, Institute of Regional Development (IDR), IREC, Campus Universitario sn, 02071 Albacete, Spain. E-mail: MRocio.Fernandez@uclm.es 


\section{Author Query Form}

Journal: RDA

Article: $\quad 1677$

Dear Author,

During the copy-editing of your paper, the following queries arose. Please respond to these by marking up your proofs with the necessary changes/additions. Please write your answers on the query sheet if there is insufficient space on the page proofs. Please write clearly and follow the conventions shown on the attached corrections sheet. If returning the proof by fax do not write too close to the paper's edge. Please remember that illegible mark-ups may delay publication.

Many thanks for your assistance.

\begin{tabular}{|l|l|l|}
\hline $\begin{array}{l}\text { Query } \\
\text { reference }\end{array}$ & Query & Remarks \\
\hline Q1 & $\begin{array}{l}\text { AUTHOR: Please specify whether Dominguez-Rebolledo et al. (2010) } \\
\text { belongs to “2010a" or “2010b". }\end{array}$ & \\
\hline Q2 & AUTHOR: Please check the expansion for LPO throughout the article. & \\
\hline Q3 & AUTHOR: Please define IVF. & \\
\hline Q4 & $\begin{array}{l}\text { AUTHOR: Please supply a conflict of interest statement (in accordance with } \\
\text { the Author Guidelines), along with all other proof corrections. }\end{array}$ & \\
\hline Q5 & $\begin{array}{l}\text { AUTHOR: Please provide the missing details for reference Dominguez- } \\
\text { Rebolledo et al. (2010a). }\end{array}$ & \\
\hline Q6 & $\begin{array}{l}\text { AUTHOR: Figure 1 has been saved at a low resolution of 166 dpi. Please } \\
\text { resupply at 600 dpi. Check required artwork specifications at http:// } \\
\text { authorservices.wiley.com/submit_illust.asp?site=1 }\end{array}$ & \\
\hline Q7 & $\begin{array}{l}\text { AUTHOR: Figure 4 has been saved at a low resolution of 147 dpi. Please } \\
\text { resupply at 600 dpi. Check required artwork specifications at http:// } \\
\text { authorservices.wiley.com/submit_illust.asp?site=1 }\end{array}$ & \\
\hline Q8 & $\begin{array}{l}\text { AUTHOR: Figure } 5 \text { has been saved at a low resolution of 171 dpi. Please } \\
\text { resupply at 600 dpi. Check required artwork specifications at http:// } \\
\text { authorservices.wiley.com/submit_illust.asp?site=1 }\end{array}$ & \\
\hline
\end{tabular}




\section{USING E-ANNOTATION TOOLS FOR ELECTRONIC PROOF CORRECTION}

\section{Required Software}

Adobe Acrobat Professional or Acrobat Reader (version 7.0 or above) is required to e-annotate PDFs. Acrobat 8 Reader is a free download: http://www.adobe.com/products/acrobat/readstep2.html

Once you have Acrobat Reader 8 on your PC and open the proof, you will see the Commenting Toolbar (if it does not appear automatically go to Tools>Commenting>Commenting Toolbar). The Commenting Toolbar looks like this:

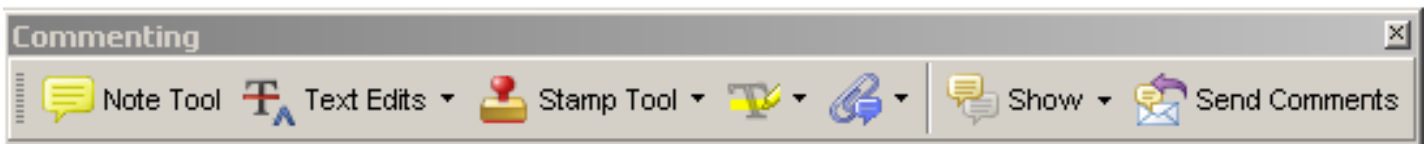

If you experience problems annotating files in Adobe Acrobat Reader 9 then you may need to change a preference setting in order to edit.

In the "Documents" category under "Edit - Preferences", please select the category 'Documents' and change the setting "PDF/A mode:" to "Never".

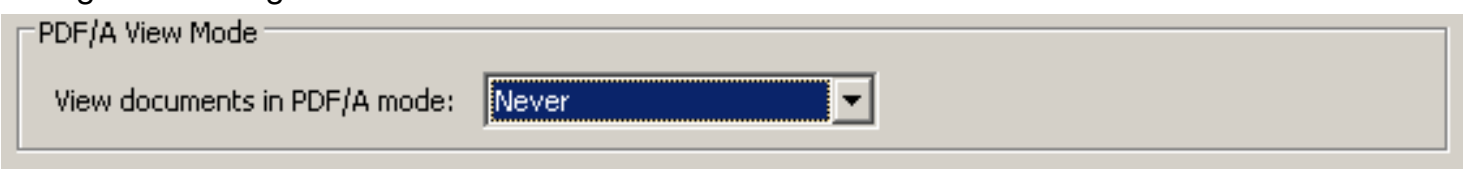

\section{Note Tool - For making notes at specific points in the text}

Marks a point on the paper where a note or question needs to be addressed.

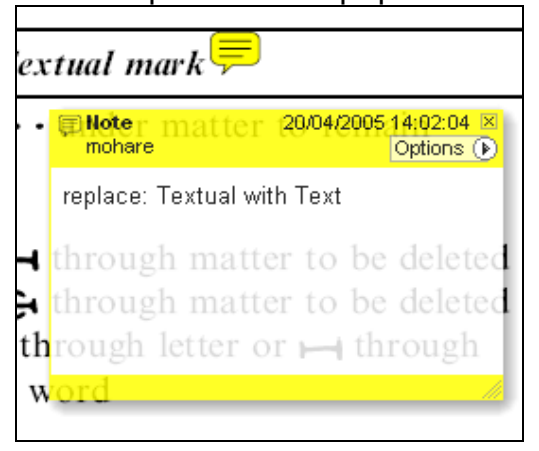

How to use it:

1. Right click into area of either inserted text or relevance to note

2. Select Add Note and a yellow speech bubble symbol and text box will appear

3. Type comment into the text box

4. Click the $X$ in the top right hand corner of the note box to close.

Replacement text tool - For deleting one word/section of text and replacing it

Strikes red line through text and opens up a replacement text box.

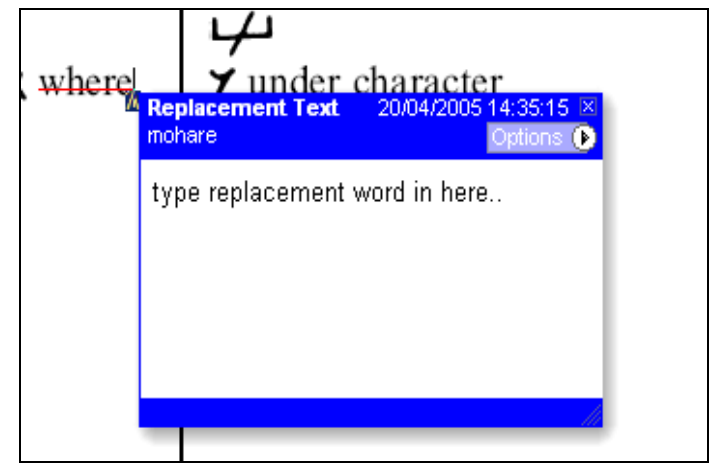

\section{How to use it:}

1. Select cursor from toolbar

2. Highlight word or sentence

3. Right click

4. Select Replace Text (Comment) option

5. Type replacement text in blue box

6. Click outside of the blue box to close

Cross out text tool - For deleting text when there is nothing to replace selection Strikes through text in a red line.

\begin{tabular}{|l|}
\hline substitute part of one or \\
more word(s) \\
Change to italies \\
Change to capitals \\
Change to small capitals \\
\hline
\end{tabular}
How to use it:
1. Select cursor from toolbar
2. Highlight word or sentence
3. Right click
4. Select Cross Out Text 


\section{(W)WILEY-BLACKWELL}

Approved tool - For approving a proof and that no corrections at all are required.

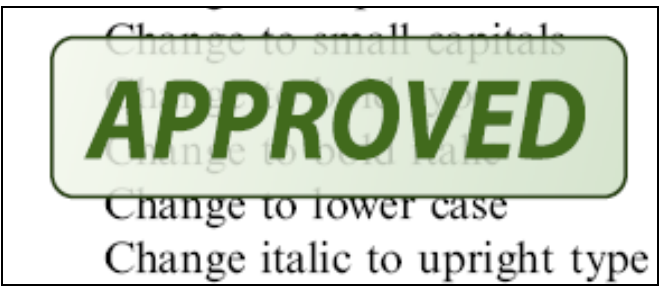

How to use it:

1. Click on the Stamp Tool in the toolbar

2. Select the Approved rubber stamp from the 'standard business' selection

3. Click on the text where you want to rubber stamp to appear (usually first page)

Highlight tool — For highlighting selection that should be changed to bold or italic. Highlights text in yellow and opens up a text box.

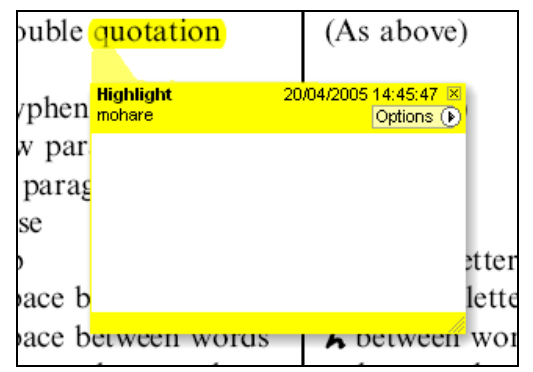

How to use it:

1. Select Highlighter Tool from the commenting toolbar

2. Highlight the desired text

3. Add a note detailing the required change

Attach File Tool - For inserting large amounts of text or replacement figures as a files. Inserts symbol and speech bubble where a file has been inserted.

\section{matter to be changed matter to matter to be changed matter to be changed} How to use it:

1. Click on paperclip icon in the commenting toolbar

2. Click where you want to insert the attachment

3. Select the saved file from your PC/network

4. Select appearance of icon (paperclip, graph, attachment or tag) and close

\section{Pencil tool - For circling parts of figures or making freeform marks}

Creates freeform shapes with a pencil tool. Particularly with graphics within the proof it may be useful to use the Drawing Markups toolbar. These tools allow you to draw circles, lines and comment on these marks.

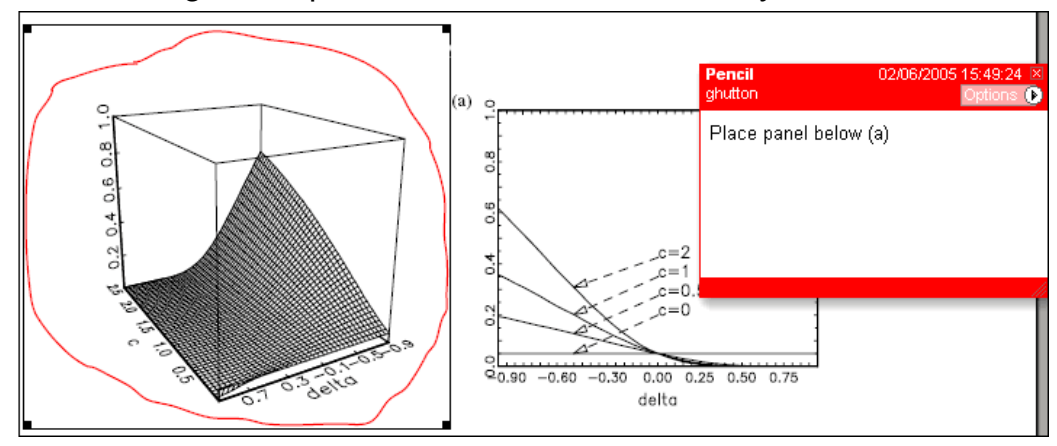

How to use it:

1. Select Tools $>$ Drawing Markups $>$ Pencil Tool

2. Draw with the cursor

3. Multiple pieces of pencil annotation can be grouped together

4. Once finished, move the cursor over the shape until an arrowhead appears and right click

5. Select Open Pop-Up Note and type in a details of required change

6. Click the $\mathrm{X}$ in the top right hand corner of the note box to close. 


\section{WILEY-BLACKWELL}

Help

For further information on how to annotate proofs click on the Help button to activate a list of instructions:

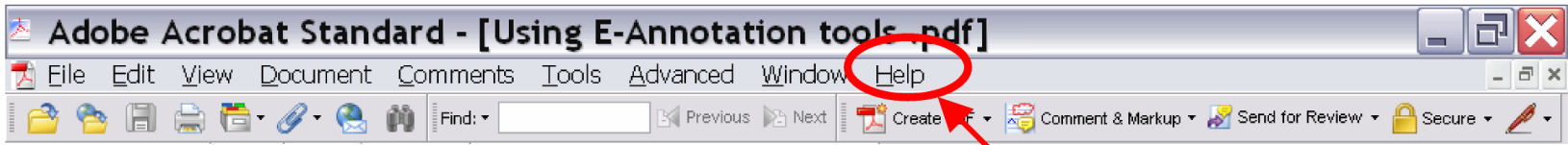

